Article

\title{
Increased Risk of Chronic Periodontitis in Chronic Rhinosinusitis Patients: A Longitudinal Follow-Up Study Using a National Health-Screening Cohort
}

\author{
Soo Hwan Byun ${ }^{1}$, Chanyang Min ${ }^{2,3}{ }^{(\mathbb{D}}$, Il Seok Park ${ }^{4}{ }^{\circ}$, Heejin Kim ${ }^{4}$, Sung Kyun Kim ${ }^{4}$, \\ Bum Jung Park ${ }^{5}$, Hyo Geun Choi ${ }^{2,5, *}$ and Seok Jin Hong ${ }^{4, *}$ \\ 1 Department of Oral \& Maxillofacial Surgery, Dentistry, Sacred Heart Hospital, \\ Hallym University College of Medicine, Anyang 14068, Korea; purheit@daum.net \\ 2 Hallym Data Science Laboratory, Hallym University College of Medicine, Anyang 14068, Korea; \\ joicemin@naver.com \\ 3 Graduate School of Public Health, Seoul National University, Seoul 03080, Korea \\ 4 Department of Otorhinolaryngology-Head \& Neck Surgery, Dongtan Sacred Heart Hospital, \\ Hallym University College of Medicine, Dongtan 18450, Korea; ispark@hallym.or.kr (I.S.P.); \\ mir5020@hallym.or.kr (H.K.); newearera@hallym.or.kr (S.K.K.) \\ 5 Department of Otorhinolaryngology-Head \& Neck Surgery, Sacred Heart Hospital, Hallym \\ University College of Medicine, Anyang 14068, Korea; bumjung426@gmail.com \\ * Correspondence: pupen@naver.com (H.G.C.); enthsj@hanmail.net (S.J.H.)
}

Received: 24 March 2020; Accepted: 15 April 2020; Published: 19 April 2020 updates

\begin{abstract}
This study compared the risk of chronic periodontitis (CP) between chronic rhinosinusitis (CRS) and non-chronic rhinosinusitis (control) patients using a national cohort dataset from the Korean Health Insurance Review and Assessment Service. CRS $(n=5951)$ and control participants ( $n=23,804)$ were selected after 1:4 ratio matching for age, sex, income, region of residence, and preoperative $\mathrm{CP}$ visits. Postoperative $\mathrm{CP}$ visits were measured between 2002 and 2015. The margin of equivalence of the difference between the CRS and control groups was set between -0.5 and 0.5. Statistical significance was noted in the post-index date (ID) of the third, fourth, and fifth year periods. In subgroup analyses according to age and sex, statistical significance was observed in 40-59-year-old males in post-ID third, fourth, and fifth year periods, $\geq 60$-year-old males in post-ID third and fourth year periods, and $\geq 60$-year-old females in post-ID fifth year period ( $p<0.05$, each). In another subgroup analysis based on the number of pre-ID CP visits, statistical significance was observed for pre-ID CP ( 0 time) in the third, fourth, and fifth year periods ( $p<0.05$, each). This study revealed that CRS participants were likely to receive $\mathrm{CP}$ diagnosis and treatment.
\end{abstract}

Keywords: rhinosinusitis; rhinitis; periodontitis; inflammation; microbiota; bacteria; cohort; korean national health screening; systemic diseases

\section{Introduction}

Chronic rhinosinusitis (CRS) is one of the most prevalent diseases of the upper respiratory tract. The prevalence of adult CRS in the Korean population was $8.4 \%$ in a study analyzing five-year cross-sectional data from the Korean National Health and Nutrition Examination Survey [1]. CRS is one of the most prevalent chronic conditions in the United States, and the prevalence of adult CRS is $12.5 \%$ in the US population [2]. European position paper on rhinosinusitis (EPOS) 2012 defined CRS as an inflammation of the nose and paranasal sinuses characterized by two or more symptoms, one of which should be either nasal blockage/obstruction/congestion or nasal discharge (anterior/posterior nasal drip): \pm facial pain/pressure \pm reduction or loss of sense of smell [3]. 
Although the pathogenesis of CRS has not been clarified, the hypothesis is that the etiology could be related to abnormalities in the epithelial barrier function and mucociliary clearance, bacterial biofilms, tissue remodeling, the host innate and adaptive immune system, and microbiome dysbiosis [4]. CRS is considered a chronic inflammatory disease rather than infection, wherein commensal resident microbiota and pathogenic microbiota could play a crucial role in the initiation and progression of the mucosal inflammation $[5,6]$.

Chronic periodontitis $(\mathrm{CP})$ is an inflammatory disease of the gingiva, accompanied by the loss of supportive connective tissues, including the periodontal ligament and alveolar bone [7]. Worsening of periodontitis results in tooth mobility and loss. CP is highly prevalent, affecting about $35 \%$ of adults $>30$ years of age [8]. Periodontal disease is a common disease affecting approximately $47.2 \%$ (or 64.7 million) of the US adult population aged $\geq 30$ years [9]. The pathogenesis of periodontitis involves complex interactions between bacteria, genetic factors, and environmental factors. Bacteria can initiate inflammatory reactions through interactions between pathogen-associated molecular patterns and pattern recognition receptors [10]. The most prevalent anaerobic Gram-negative bacteria involved in periodontitis are Actinobacillus actinomycetemcomitans, Porphyromonas gingivalis, Prevotella intermedia, and Tannerella forsythensis [11]. These bacteria play an important role in the onset and progression of periodontitis, formation of periodontal pockets, connective tissue destruction, and alveolar bone loss through immunologic and pathogenic mechanisms. Once periodontitis has been initiated, an inflammatory factor produces various cytokine subtypes and biological elements responsible for immunologic and pathogenic reactions. Microorganisms usually proliferate on dental surfaces in the form of plaque. A plaque is an agglomeration of biofilm, which is known to be a phenotype of bacteria. The spread of biofilms is of great clinical importance in periodontitis, since it is resistant to antimicrobial agents $[12,13]$.

CRS and CP exhibit some common characteristics. Both are chronic conditions, and the polymicrobial biofilms are stabilized in the airway of patients with CRS or in the oral cavity of patients with CP. Previous large population studies have attempted to explain the association between CRS and CP by taking into account these similar characteristics [14,15].

The purpose of this study was to compare the risk of $\mathrm{CP}$ between the chronic rhinosinusitis (CRS group) and non-chronic rhinosinusitis (control group) participants using a national cohort dataset. In this study, the CRS and control groups were matched at a 1:4 ratio by adjusting for age, sex, region of residence, pre-index $\mathrm{CP}$ treatment, obesity, smoking, alcohol consumption, and Charlson comorbidity index (CCI) score.

\section{Materials and Methods}

\subsection{Study Population}

The study was approved by the ethics committee of Hallym University (2017-I102) and written informed consent was waived by the Institutional Review Board. All analyses adhered to the guidelines and regulations of the ethics committee of Hallym University. A detailed description of the Korean National Health Insurance Service-Health Screening Cohort data has been described previously [16].

\subsection{Chronic Rhinosinusitis}

CRS was defined using the 10th International Statistical Classification of Diseases and Related Health Problems (ICD-10) codes (J32). We selected participants who were treated $\geq 2$ times, and those who underwent head and neck computed tomography evaluations (Claim codes: HA401-HA416, HA441-HA443, HA451-HA453, HA461-HA463, or HA471-HA473). Among the CRS patients, 4423 were treated for nasal polyps (J33), while the other 4137 participants were not. 


\subsection{Chronic Periodontitis}

$\mathrm{CP}$ was defined based on the ICD-10 codes (K05.3) and treated by dentists. The number of CP treatments was counted from the date of CRS treatment (index date [ID]) to the date before the 2-year period (pre-ID CP for $2 \mathrm{y}$ ). The number of $\mathrm{CP}$ treatments was counted for periods from the ID to the date up to the end of the first year (post-ID 1 y CP, postoperative 1-365 days), second year (post-ID 2 y CP, postoperative 366-730 days), third year (post-ID 3 y CP, postoperative 731-1095 days), fourth year (post-ID 4 y CP, postoperative 1,096-1,460 days), and fifth year (post-ID $5 \mathrm{y} \mathrm{CP}$, postoperative 1461-1825 days).

\subsection{Participant Selection}

CRS patients were selected from 514,866 participants with 497,931,549 medical claim codes $(n=8560)$. The control group included participants who did not have CRS from 2002 to 2015 $(n=506,306)$. To select CRS patients who were diagnosed for the first time, we excluded CRS patients diagnosed between 2002 and 2003 (washout periods, $n=2395$ ). CRS patients were matched at a 1:4 ratio with control group participants for age, sex, income, and region of residence. To analyze subgroups according to pre-ID CP for $2 \mathrm{y}$, CRS patients were additionally matched with pre-ID CP for $2 \mathrm{y}$ with categorical variables ( 0 time, 1 time, and $\geq 2$ times). To minimize selection bias, the control participants were randomly selected. The ID of each CRS patient was set as the date of their CRS treatment. The ID of the control participants was set as that of their matched CRS patients. Therefore, each CRS patient matched with a control participant had the same ID as the latter. During the 1:4 matching procedure, 481,646 un-matched control participants were excluded. Participants recorded in 2015 were excluded to calculate post-ID 1 y CP ( $\mathrm{n}=214$ for CRS patients, $\mathrm{n}=856$ for control participants). Finally, 5951 CRS patients with or without nasal polyps were matched (1:4 ratio) with 23,804 control participants (Figure 1).

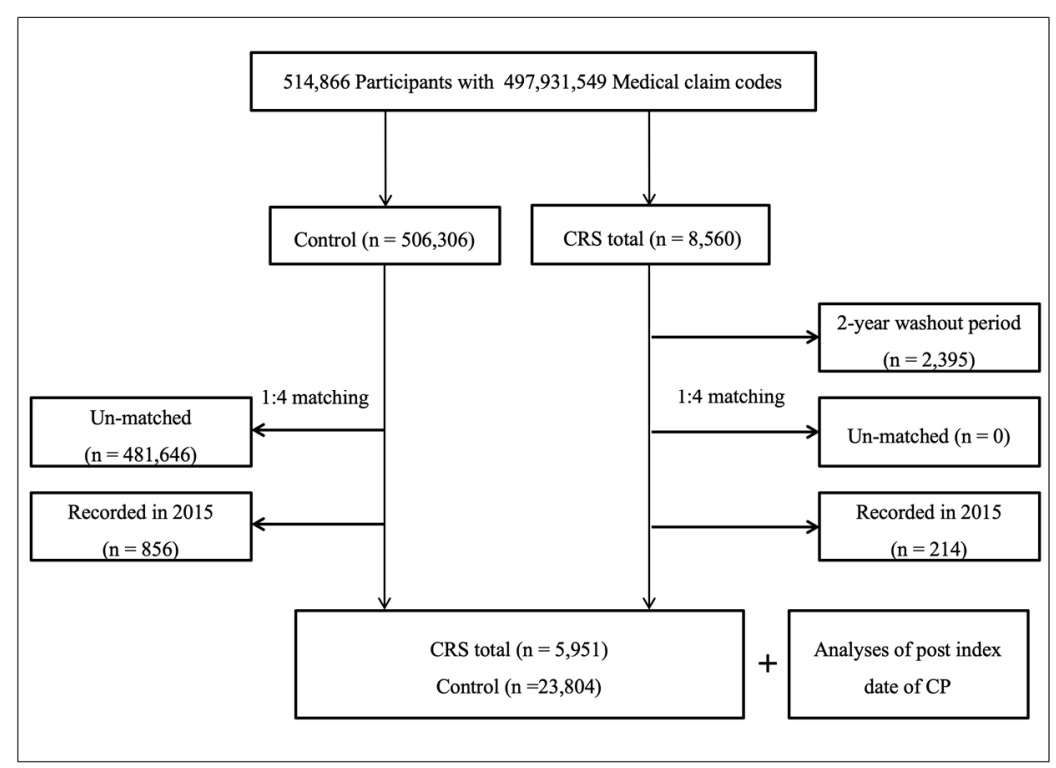

Figure 1. Schematic illustration of the participant selection process used in the present study. Out of 514,866 participants, 5951 chronic rhinosinusitis patients were matched with 23,804 control participants for age, sex, income, region of residence, and pre-index date chronic periodontitis for 2 years.

\subsection{Other Variables}

Age groups were divided into 5-year intervals, and ten age groups $(40-44,45-49,50-54 \ldots$, and $85+$ years) were specified. Income groups were classified into five classes (class 1: lowest income to class 5: highest income). The regions of residence were grouped into urban (Seoul, Busan, Daegu, Incheon, 
Gwangju, Daejeon, and Ulsan) and rural (Gyeonggi, Gangwon, Chungcheongbuk, Chungcheongnam, Jeollabuk, Jeollanam, Gyeongsangbuk, Gyeongsangnam, and Jeju) areas.

Tobacco smoking was categorized based on the participant's current smoking status (non-smoker, past smoker, and current smoker). Alcohol consumption was categorized based on the frequency of alcohol consumption ( $<1$ time a week and $\geq 1$ time a week). Obesity was measured using body mass index $\left(\mathrm{BMI}, \mathrm{kg} / \mathrm{m}^{2}\right)$. Missing BMI variables were replaced by the mean BMI of the final selected participants. BMI was categorized as $<18.5$ (underweight), $\geq 18.5$ to $\leq 23$ (normal), $\geq 23$ to $<25$ (overweight), $\geq 25$ to $<30$ (obese I), and $\geq 30$ (obese II) based on the Asia-Pacific criteria following the Western Pacific Regional Office 2000.

The CCI has been widely used to measure disease burden using 17 comorbidities. A score was given to each participant depending on the severity and number of diseases. CCI was measured as a continuous variable ( 0 (no comorbidities) through 29 (multiple comorbidities)) [17,18]. The scores were calculated after the exclusion of cerebrovascular diseases. The CCI score was used as a covariate in the analyses.

\subsection{Statistical Analyses}

The general characteristics between the CRS and control groups were compared using the chi-square test. Simple and multiple linear regressions were used to calculate estimated values and $95 \%$ confidence intervals (CI) for post-ID 1 y CP, post-ID 2 y CP, post-ID 3 y CP, post-ID 4 y CP, and post-ID 5 y CP, in CRS patients with or without nasal polyps, and compared to the control group. Simple and multiple linear regressions were stratified by age, sex, income, and region of residence. In multiple linear regression, the model was adjusted for obesity, smoking status, alcohol consumption, CCI score, and pre-ID CP for $2 \mathrm{y}$ with continuous variables.

For the subgroup analyses, we divided participants by age ( $<60$ years old and $\geq 60$ years old), sex (male and female), and pre-ID CP for 2 y ( 0 time, 1 time, and $\geq 2$ times variables) and analyzed the crude and adjusted models.

Two-tailed analyses were performed, and significance was defined as a $p$-value $<0.05$. SAS version 9.4 (SAS Institute Inc., Cary, NC, USA) was used for statistical analyses.

\section{Results}

Age, sex, income, and region of residence were similar in the CRS and control groups $(p=1.000)$, while smoking and CCI scores were different between both groups $(p<0.05$, Table 1$)$.

Table 1. General Characteristics of Participants.

\begin{tabular}{cccc}
\hline Characteristics & \multicolumn{3}{c}{ Total Participants } \\
\hline & CRS Total (n, \%) & Control (n, \%) & $p$-Value \\
\hline Age (years old) & $233(3.9)$ & $932(3.9)$ & 1.000 \\
$40-44$ & $972(16.3)$ & $3888(16.3)$ & \\
$45-49$ & $1323(22.2)$ & $5292(22.2)$ & \\
$50-54$ & $1245(20.9)$ & $4980(20.9)$ & \\
$55-59$ & $934(15.7)$ & $3736(15.7)$ & \\
$60-64$ & $671(11.3)$ & $2684(11.3)$ & \\
$65-69$ & $363(6.1)$ & $1452(6.1)$ & \\
$70-74$ & $159(2.7)$ & $636(2.7)$ & \\
$75-79$ & $40(0.7)$ & $160(0.7)$ & \\
$80-84$ & $11(0.2)$ & $44(0.2)$ & \\
$85+$ & & & \\
Sex & $3650(61.3)$ & $14,600(61.3)$ & \\
Male & $2301(38.7)$ & $9204(38.7)$ & \\
Female & & & \\
Income & &
\end{tabular}


Table 1. Cont.

\begin{tabular}{|c|c|c|c|}
\hline \multirow[t]{2}{*}{ Characteristics } & \multicolumn{3}{|c|}{ Total Participants } \\
\hline & CRS Total (n, \%) & Control (n, \%) & $p$-Value \\
\hline 1 (lowest) & $720(12.1)$ & $2880(12.1)$ & \\
\hline 2 & 708 (11.9) & $2832(11.9)$ & \\
\hline 3 & $905(15.2)$ & $3620(15.2)$ & \\
\hline 4 & $1294(21.7)$ & $5176(21.7)$ & \\
\hline 5 (highest) & $2324(39.1)$ & $9296(39.1)$ & \\
\hline Region of residence & & & 1.000 \\
\hline Urban & $2762(46.4)$ & $11,048(46.4)$ & \\
\hline Rural & $3189(53.6)$ & $12,756(53.6)$ & \\
\hline Pre index date of $\mathrm{CP}$ & & & 1.000 \\
\hline 0 time & $3818(64.2)$ & $15,272(64.2)$ & \\
\hline 1 time & $895(15.0)$ & $3580(15.0)$ & \\
\hline$\geq 2$ times & $1238(20.8)$ & $4952(20.8)$ & \\
\hline Obesity $^{\dagger}$ & & & 0.183 \\
\hline Underweight & $101(1.7)$ & $445(1.9)$ & \\
\hline Normal & $1933(32.5)$ & 8024 (33.7) & \\
\hline Overweight & $1780(29.9)$ & $6783(28.5)$ & \\
\hline Obese I & $1973(33.2)$ & 7897 (33.2) & \\
\hline Obese II & $164(2.8)$ & $655(2.8)$ & \\
\hline Smoking status & & & $0.004 *$ \\
\hline Nonsmoker & $3918(65.8)$ & $15,582(65.5)$ & \\
\hline Past smoker & $858(14.4)$ & $3142(13.2)$ & \\
\hline Current smoker & 1175 (19.7) & $5080(21.3)$ & \\
\hline Alcohol consumption & & & 0.858 \\
\hline$<1$ time a week & $3972(66.8)$ & $15,917(66.9)$ & \\
\hline$\geq 1$ time a week & $1979(33.3)$ & $7887(33.1)$ & \\
\hline CCI score & & & $<0.001 *$ \\
\hline 0 & $3842(64.6)$ & $16,956(71.2)$ & \\
\hline 1 & $965(16.2)$ & $3173(13.3)$ & \\
\hline 2 & $544(9.1)$ & $1683(7.1)$ & \\
\hline 3 & $263(4.4)$ & $841(3.5)$ & \\
\hline$\geq 4$ & $337(5.7)$ & $1151(4.8)$ & \\
\hline CRS total & $5951(100.0)$ & $0(0.0)$ & $<0.001^{*}$ \\
\hline CRS with nasal polyp & $2891(100.0)$ & $0(0.0)$ & $<0.001 *$ \\
\hline CRS without nasal polyp & $3060(100.0)$ & $0(0.0)$ & $<0.001 *$ \\
\hline
\end{tabular}

Abbreviations: CCI, Charlson comorbidity index; $\mathrm{CP}$, chronic periodontitis; CRS, Chronic Rhinosinusitis. ${ }^{*} \chi^{2}$ test. Significance at $p<0.05 .^{\dagger}$ Obesity (BMI, body mass index, $\mathrm{kg} / \mathrm{m}^{2}$ ) was categorized as $<18.5$ (underweight), $\geq 18.5$ to $<23$ (normal), $\geq 23$ to $<25$ (overweight), $\geq 25$ to $<30$ (obese I), and $\geq 30$ (obese II).

The number of $\mathrm{CP}$ cases before the ID was matched as the categorical variable. The adjusted estimated value (EV) of the number of post-ID CP cases did not reach statistical significance in post-ID $1 \mathrm{y}$ and $2 \mathrm{y}(p>0.05$, each; Table 2$)$.

However, it showed statistical significance for 3 y $(E V=0.071,95 \% C I=0.030-0.113), 4 \mathrm{y}$ $(\mathrm{EV}=0.085,95 \% \mathrm{CI}=0.040-0.130)$, and $5 \mathrm{y}(\mathrm{EV}=0.057,95 \% \mathrm{CI}=0.009-0.106 ; p<0.05$, each $)$

In the subgroup analyses according to age and sex, statistical significance was seen in 40-59-year-old males in post-ID $3 \mathrm{y}, 4 \mathrm{y}$, and $5 \mathrm{y}$ periods, $\geq 60$-year-old males in post-ID $3 \mathrm{y}$ and $4 \mathrm{y}$ periods, and $\geq 60$-year-old females in post-ID 5 y period ( $p<0.05$, each; Table 3 ).

In another subgroup analysis according to the number of pre-ID CP cases, a statistical significance for pre-ID CP (0 time) in post ID $3 \mathrm{y}, 4 \mathrm{y}$, and $5 \mathrm{y}$ was found ( $p<0.05$, each; Table 4$)$. 
Table 2. Simple and multiple linear regression model (estimated value (95\% confidence interval)) for post index date of $\mathrm{CP}$ (post-ID CP) periods in CRS with/without nasal polyp (total) group compared to control group.

\begin{tabular}{|c|c|c|c|c|}
\hline \multirow[t]{2}{*}{ Characteristics } & \multicolumn{4}{|c|}{ Linear Regression } \\
\hline & Simple ${ }^{\dagger}$ & $p$-Value & Multiple ${ }^{\dagger \ddagger}$ & $p$-Value \\
\hline \multicolumn{5}{|c|}{ Post ID 1 y CP $(\mathrm{n}=29,755)$} \\
\hline CRS total & $0.015(-0.021$ to 0.051$)$ & 0.417 & $0.005(-0.029$ to 0.040$)$ & 0.763 \\
\hline \multicolumn{5}{|c|}{ Post ID 2 y CP $(n=28,530)$} \\
\hline CRS total & $0.004(-0.035$ to 0.043$)$ & 0.841 & $-0.003(-0.041$ to 0.035$)$ & 0.867 \\
\hline \multicolumn{5}{|c|}{ Post ID 3 y CP $(n=26,820)$} \\
\hline CRS total & $0.078(0.035$ to 0.120$)$ & $<0.001 *$ & 0.071 (0.030 to 0.113$)$ & $0.001 *$ \\
\hline \multicolumn{5}{|c|}{ Post ID 4 y CP $(n=25,000)$} \\
\hline CRS total & 0.087 (0.041 to 0.132$)$ & $<0.001 *$ & $0.085(0.040$ to 0.130$)$ & $<0.001$ * \\
\hline \multicolumn{5}{|c|}{ Post ID 5 y CP $(n=22,660)$} \\
\hline CRS total & 0.060 (0.011 to 0.109$)$ & $0.017 *$ & $0.057(0.009$ to 0.106$)$ & $0.020 *$ \\
\hline
\end{tabular}

Abbreviations: CCI, Charlson comorbidity index; CP, chronic periodontitis; CRS, Chronic Rhinosinusitis. * Linear regression model, Significance at $p<0.05 .{ }^{\dagger}$ Models stratified by age, sex, income, and region of residence. $¥$ A model adjusted for obesity, smoking, alcohol consumption, CCI scores, and pre index date of CP (pre-ID CP) for $2 \mathrm{y}$.

Table 3. Subgroup analyses of simple and multiple linear regression model (estimated value (95\% confidence interval)) for post index date of CP (post-ID CP) periods in CRS with/without nasal polyp group compared to control group according to age and sex.

\begin{tabular}{|c|c|c|c|c|}
\hline & \multicolumn{4}{|c|}{ Linear Regression } \\
\hline & Simple ${ }^{\dagger}$ & $p$-Value & Multiple $† \ddagger$ & $p$-Value \\
\hline \multicolumn{5}{|c|}{ Age $40-59$ years old males } \\
\hline \multicolumn{5}{|c|}{ Post-ID 1 y CP $(n=12,035$, Mean $\pm S D=0.46 \pm 1.19$ for CRS, Mean $\pm S D=0.48 \pm 1.31$ for control $)$} \\
\hline CRS total & $-0.020(-0.077$ to 0.037$)$ & 0.496 & $-0.037(-0.093$ to 0.018$)$ & 0.186 \\
\hline \multicolumn{5}{|c|}{ Post-ID 2 y CP $(n=11,635$, Mean $\pm S D=0.54 \pm 1.37$ for CRS, Mean $\pm S D=0.53 \pm 1.43$ for control $)$} \\
\hline CRS total & $0.009(-0.055$ to 0.073$)$ & 0.777 & $-0.003(-0.066$ to 0.060$)$ & 0.933 \\
\hline \multicolumn{5}{|c|}{ Post-ID 3 y CP $(n=11,180$, Mean $\pm S D=0.63 \pm 1.56$ for CRS, Mean $\pm S D=0.54 \pm 1.40$ for control $)$} \\
\hline CRS total & $0.084(0.017$ to 0.150$)$ & $0.013^{*}$ & $0.074(0.009$ to 0.139$)$ & $0.027 *$ \\
\hline \multicolumn{5}{|c|}{ Post-ID 4 y CP $(n=10,565$, Mean $\pm S D=0.70 \pm 1.62$ for CRS, Mean $\pm S D=0.61 \pm 1.53$ for control } \\
\hline CRS total & $0.097(0.023$ to 0.170$)$ & $0.010^{*}$ & $0.090(0.017$ to 0.163$)$ & $0.015 *$ \\
\hline \multicolumn{5}{|c|}{ Post-ID 5 y CP $(n=9705$, Mean $\pm S D=0.70 \pm 1.60$ for CRS, Mean $\pm S D=0.65 \pm 1.55$ for control $)$} \\
\hline CRS total & $0.055(-0.022$ to 0.133$)$ & 0.164 & $0.044(-0.033$ to 0.121$)$ & 0.263 \\
\hline \multicolumn{5}{|c|}{ Age $40-59$ years old females } \\
\hline \multicolumn{5}{|c|}{ Post-ID 1 y CP $(n=6830$, Mean $\pm S D=0.44 \pm 1.30$ for CRS, Mean $\pm S D=0.37 \pm 1.07$ for control $)$} \\
\hline CRS total & $0.065(-0.001$ to 0.131$)$ & 0.054 & $0.065(0.002$ to 0.129$)$ & $0.043 *$ \\
\hline \multicolumn{5}{|c|}{ Post-ID 2 y CP $(n=6690$, Mean $\pm S D=0.42 \pm 1.11$ for CRS, Mean $\pm S D=0.41 \pm 1.20$ for control $)$} \\
\hline CRS total & $0.010(-0.061$ to 0.080$)$ & 0.788 & $0.008(-0.061$ to 0.078$)$ & 0.817 \\
\hline \multicolumn{5}{|c|}{ Post-ID 3 y $C P(n=6420$, Mean $\pm S D=0.50 \pm 1.25$ for $C R S$, Mean $\pm S D=0.47 \pm 1.32$ for control $)$} \\
\hline CRS total & $0.030(-0.050$ to 0.109$)$ & 0.467 & $0.031(-0.048$ to 0.110$)$ & 0.441 \\
\hline \multicolumn{5}{|c|}{ Post-ID 4 y $C P(n=6,095$, Mean $\pm S D=0.47 \pm 1.20$ for $C R S$, Mean $\pm S D=0.49 \pm 1.31$ for control $)$} \\
\hline CRS total & $-0.018(-0.098$ to 0.063$)$ & 0.669 & $-0.015(-0.095$ to 0.064$)$ & 0.705 \\
\hline \multicolumn{5}{|c|}{ Post-ID 5 y CP $(\mathrm{n}=5615$, Mean $\pm \mathrm{SD}=0.55 \pm 1.21$ for $\mathrm{CRS}$, Mean $\pm \mathrm{SD}=0.54 \pm 1.40$ for control $)$} \\
\hline CRS total & $0.006(-0.082$ to 0.095$)$ & 0.887 & $0.012(-0.076$ to 0.100$)$ & 0.790 \\
\hline \multicolumn{5}{|c|}{ Age $\geq 60$ years old males } \\
\hline \multicolumn{5}{|c|}{ Post-ID 1 y CP $(\mathrm{n}=6215$, Mean $\pm \mathrm{SD}=0.65 \pm 1.56$ for CRS, Mean $\pm \mathrm{SD}=0.57 \pm 1.39$ for control $)$} \\
\hline CRS total & $0.083(-0.005$ to 0.172$)$ & 0.064 & $0.079(-0.005$ to 0.163$)$ & 0.066 \\
\hline \multicolumn{5}{|c|}{ Post-ID 2 y CP $(\mathrm{n}=5795$, Mean $\pm \mathrm{SD}=0.64 \pm 1.37$ for CRS, Mean $\pm \mathrm{SD}=0.62 \pm 1.49$ for control $)$} \\
\hline CRS total & $0.013(-0.082$ to 0.107$)$ & 0.795 & $0.006(-0.086$ to 0.097$)$ & 0.900 \\
\hline \multicolumn{5}{|c|}{ Post-ID 3 y CP $(n=5225$, Mean $\pm S D=0.80 \pm 1.74$ for CRS, Mean $\pm S D=0.63 \pm 1.51$ for control $)$} \\
\hline CRS total & $0.172(0.066$ to 0.277$)$ & $0.002 *$ & $0.165(0.062$ to 0.268$)$ & $0.002 *$ \\
\hline \multicolumn{5}{|c|}{ Post-ID 4 y CP $(n=4670$, Mean $\pm S D=0.81 \pm 1.86$ for CRS, Mean $\pm S D=0.61 \pm 1.52$ for control $)$} \\
\hline CRS total & $0.198(0.085$ to 0.312$)$ & $0.001 *$ & $0.195(0.083$ to 0.307$)$ & $0.001 *$ \\
\hline \multicolumn{5}{|c|}{ Post-ID 5 y CP $(n=4030$, Mean $\pm S D=0.77 \pm 1.83$ for CRS, Mean $\pm S D=0.68 \pm 1.68$ for control $)$} \\
\hline CRS total & $0.086(-0.046$ to 0.217$)$ & 0.203 & $0.088(-0.041$ to 0.218$)$ & 0.182 \\
\hline
\end{tabular}


Table 3. Cont.

\begin{tabular}{|c|c|c|c|c|}
\hline & \multicolumn{4}{|c|}{ Linear Regression } \\
\hline & Simple $^{+}$ & $p$-Value & Multiple ${ }^{\dagger \ddagger}$ & $p$-Value \\
\hline \multicolumn{5}{|c|}{ Age $\geq 60$ years old females } \\
\hline \multicolumn{5}{|c|}{ Post-ID 1 y $C P(n=4675$, Mean $\pm S D=0.42 \pm 1.13$ for $C R S$, Mean $\pm S D=0.48 \pm 1.23$ for control $)$} \\
\hline CRS total & $-0.060(-0.147$ to 0.027$)$ & 0.175 & $-0.066(-0.150$ to 0.017$)$ & 0.120 \\
\hline \multicolumn{5}{|c|}{ Post-ID 2 y CP $(n=4410$, Mean $\pm S D=0.43 \pm 1.08$ for CRS, Mean $\pm S D=0.46 \pm 1.28$ for control } \\
\hline CRS total & $-0.030(-0.121$ to 0.062$)$ & 0.523 & $-0.033(-0.122$ to 0.056$)$ & 0.464 \\
\hline \multicolumn{5}{|c|}{ Post-ID 3 y CP $(\mathrm{n}=3995$, Mean $\pm \mathrm{SD}=0.51 \pm 1.59$ for CRS, Mean $\pm \mathrm{SD}=0.49 \pm 1.28$ for control } \\
\hline CRS total & $0.015(-0.089$ to 0.119$)$ & 0.773 & $0.009(-0.093$ to 0.112$)$ & 0.856 \\
\hline \multicolumn{5}{|c|}{ Post-ID 4 y CP $(\mathrm{n}=3670$, Mean $\pm \mathrm{SD}=0.57 \pm 1.58$ for CRS, Mean $\pm \mathrm{SD}=0.49 \pm 1.28$ for control $)$} \\
\hline CRS total & $0.089(-0.020$ to 0.198$)$ & 0.109 & $0.089(-0.019$ to 0.196$)$ & 0.106 \\
\hline \multicolumn{5}{|c|}{ Post-ID 5 y CP $(n=3310$, Mean $\pm S D=0.63 \pm 1.53$ for CRS, Mean $\pm S D=0.50 \pm 1.25$ for control $)$} \\
\hline CRS total & 0.131 (0.019 to 0.243$)$ & $0.022 *$ & $0.136(0.025$ to 0.247$)$ & 0.017 * \\
\hline
\end{tabular}

Abbreviations: CCI, Charlson comorbidity index; CP, chronic periodontitis; CRS, Chronic Rhinosinusitis. * Linear regression model, Significance at $p<0.05 .{ }^{\dagger}$ Models stratified by age, sex, income, and region of residence. ${ }^{\ddagger}$ A model adjusted for obesity, smoking, alcohol consumption, CCI scores, and pre index date of CP (pre-ID CP) for $2 \mathrm{y}$.

Table 4. Subgroup analyses of simple and multiple linear regression model (estimated value [95\% confidence interval]) for post index date of CP (post-ID CP) periods in CRS with/without nasal polyp and control groups according to pre index date of $\mathrm{CP}$ (pre-ID CP) for 2 years.

\begin{tabular}{|c|c|c|c|c|}
\hline \multirow[t]{2}{*}{ Characteristics } & \multicolumn{4}{|c|}{ Linear Regression } \\
\hline & Simple ${ }^{\dagger}$ & $p$-Value & Multiple $† \ddagger$ & $p$-Value \\
\hline \multicolumn{5}{|c|}{ Pre-ID CP $=0$ time for 2 years } \\
\hline \multicolumn{5}{|c|}{ Post-ID 1 y CP $(n=19,090$, Mean $\pm S D=0.29 \pm 0.91$ for CRS, Mean $\pm S D=0.29 \pm 0.95$ for control } \\
\hline CRS total & $0.005(-0.029$ to 0.038$)$ & 0.780 & $0.006(-0.028$ to 0.039$)$ & 0.746 \\
\hline \multicolumn{5}{|c|}{ Post-ID 2 y CP $(n=18,530$, Mean $\pm S D=0.36 \pm 1.04$ for CRS, Mean $\pm S D=0.35 \pm 1.11$ for control } \\
\hline CRS total & $0.013(-0.027$ to 0.052$)$ & 0.525 & $0.015(-0.024$ to 0.054$)$ & 0.455 \\
\hline \multicolumn{5}{|c|}{ Post-ID 3 y CP $(n=17,665$, Mean $\pm S D=0.45 \pm 1.32$ for CRS, Mean $\pm S D=0.38 \pm 1.13$ for control } \\
\hline CRS total & 0.064 (0.021 to 0.107$)$ & $0.004 *$ & $0.065(0.022$ to 0.108$)$ & $0.003 *$ \\
\hline \multicolumn{5}{|c|}{ Post-ID 4 y CP $(n=16,715$, Mean $\pm S D=0.52 \pm 1.43$ for CRS, Mean $\pm S D=0.41 \pm 1.22$ for control } \\
\hline CRS total & $0.108(0.060$ to 0.156$)$ & $<0.001$ * & 0.111 (0.064 to 0.159$)$ & $<0.001 *$ \\
\hline \multicolumn{5}{|c|}{ Post-ID 5 y CP $(\mathrm{n}=15,410$, Mean $\pm \mathrm{SD}=0.52 \pm 1.29$ for $\mathrm{CRS}$, Mean $\pm \mathrm{SD}=0.47 \pm 1.26$ for control } \\
\hline CRS total & $0.050(0.000$ to 0.100$)$ & $0.050 *$ & $0.052(0.002$ to 0.102$)$ & $0.040 *$ \\
\hline \multicolumn{5}{|c|}{ Pre-ID CP $=1$ time for 2 years } \\
\hline \multicolumn{5}{|c|}{ Post-ID 1 y CP $(\mathrm{n}=4475$, Mean $\pm S D=0.51 \pm 1.19$ for $C R S$, Mean $\pm S D=0.54 \pm 1.27$ for control $)$} \\
\hline CRS total & $-0.030(-0.121$ to 0.062$)$ & 0.526 & $-0.029(-0.120$ to 0.063$)$ & 0.540 \\
\hline \multicolumn{5}{|c|}{ Post-ID 2 y CP $(\mathrm{n}=4270$, Mean $\pm \mathrm{SD}=0.55 \pm 1.25$ for $\mathrm{CRS}$, Mean $\pm \mathrm{SD}=0.60 \pm 1.40$ for control $)$} \\
\hline CRS total & $-0.052(-0.154$ to 0.051$)$ & 0.321 & $-0.051(-0.153$ to 0.051$)$ & 0.329 \\
\hline \multicolumn{5}{|c|}{ Post-ID 3 y $C P(n=4005$, Mean $\pm S D=0.67 \pm 1.54$ for CRS, Mean $\pm S D=0.62 \pm 1.50$ for control $)$} \\
\hline CRS total & $0.046(-0.071$ to 0.163$)$ & 0.438 & $0.053(-0.063$ to 0.170$)$ & 0.370 \\
\hline \multicolumn{5}{|c|}{ Post-ID 4 y CP $(\mathrm{n}=3665$, Mean $\pm \mathrm{SD}=0.76 \pm 1.68$ for $\mathrm{CRS}$, Mean $\pm \mathrm{SD}=0.66 \pm 1.52$ for control $)$} \\
\hline CRS total & $0.095(-0.031$ to 0.220$)$ & 0.139 & 0.097 (-0.029 to 0.223$)$ & 0.130 \\
\hline \multicolumn{5}{|c|}{ Post-ID 5 y CP $(\mathrm{n}=3265$, Mean $\pm \mathrm{SD}=0.83 \pm 1.90$ for CRS, Mean $\pm \mathrm{SD}=0.71 \pm 1.63$ for control $)$} \\
\hline CRS total & $0.125(-0.020$ to 0.269$)$ & 0.090 & 0.128 (-0.017 to 0.272$)$ & 0.083 \\
\hline \multicolumn{5}{|c|}{ Pre-ID CP $\geq 2$ times for 2 years } \\
\hline \multicolumn{5}{|c|}{ Post-ID 1 y CP $(n=6190$, Mean $\pm S D=1.08 \pm 2.02$ for CRS, Mean $\pm S D=1.00 \pm 1.82$ for control $)$} \\
\hline CRS total & $0.078(-0.038$ to 0.194$)$ & 0.186 & 0.031 (-0.081 to 0.143$)$ & 0.589 \\
\hline \multicolumn{5}{|c|}{ Post-ID 2 y CP $(n=5730$, Mean $\pm S D=1.00 \pm 1.76$ for CRS, Mean $\pm S D=0.98 \pm 1.90$ for control $)$} \\
\hline CRS total & $0.017(-0.104$ to 0.138$)$ & 0.780 & $-0.023(-0.142$ to 0.097$)$ & 0.710 \\
\hline \multicolumn{5}{|c|}{ Post-ID 3 y CP $(n=5150$, Mean $\pm S D=1.14 \pm 2.03$ for CRS, Mean $\pm S D=0.99 \pm 1.88$ for control $)$} \\
\hline CRS total & $0.148(0.017$ to 0.279$)$ & $0.027 *$ & $0.122(-0.007$ to 0.251$)$ & 0.064 \\
\hline \multicolumn{5}{|c|}{ Post-ID 4 y CP $(n=4620$, Mean $\pm S D=1.02 \pm 1.90$ for CRS, Mean $\pm S D=1.01 \pm 1.94$ for control $)$} \\
\hline CRS total & $0.003(-0.137$ to 0.142$)$ & 0.970 & $-0.013(-0.152$ to 0.126$)$ & 0.853 \\
\hline \multicolumn{5}{|c|}{ Post-ID 5 y CP $(n=3985$, Mean $\pm S D=1.09 \pm 2.02$ for CRS, Mean $\pm S D=1.05 \pm 2.04$ for control $)$} \\
\hline CRS total & $0.043(-0.115$ to 0.201$)$ & 0.592 & 0.035 (-0.123 to 0.192$)$ & 0.667 \\
\hline
\end{tabular}

Abbreviations: CCI, Charlson comorbidity index; CP, chronic periodontitis; CRS, Chronic Rhinosinusitis. * Linear regression model, Significance at $p<0.05 .{ }^{\dagger}$ Models stratified by age, sex, income, and region of residence. $\ddagger$ A model adjusted for obesity, smoking, alcohol consumption, CCI scores, and pre-ID CP for $2 \mathrm{y}$. 


\section{Discussion}

CRS and $\mathrm{CP}$ are associated with chronic inflammation. As $\mathrm{CP}$ is a widespread immunoinflammatory condition, an association between CRS and CP has been proposed. This was mainly attributed to increased levels of pro-inflammatory mediators, such as interleukin (IL)-1, IL-6, and tumor necrosis factor- $\alpha$ in the plasma [19]. Therefore, we sought to investigate the association between CRS and CP in a large population cohort.

This study revealed an increased risk for CP in post-ID three-, four-, and five-year periods following a diagnosis of CRS. In another subgroup analysis according to the number of pre-ID CP check-ups, statistical significance was observed for pre-ID CP (0 time) in post-ID three-, four-, and five-year periods. After adjusting for age, sex, income, region of residence, pre-operative $\mathrm{CP}$, obesity, smoking, alcohol consumption, and CCI score, the study showed that participants with CRS were more likely to receive a $\mathrm{CP}$ diagnosis and treatment.

Various studies have demonstrated a relationship between mouth breathing and gingivitis in teenagers [20]. We can assume that CRS may induce mouth breathing in adults. Mouth breathing is related to dry mouth, which reduces the washing out of bacteria and biofilm by salivation. Chronic mouth breathing habits cause gingival inflammation, and further progression could develop CP due to biofilm and microbiome dysbiosis. This mechanism could be one of the possible explanations for the increased risk of CP with CRS in the present study. In particular, the adjusted estimated value of the number of post-ID CP cases did not reach statistical significance one and two years post-ID. Instead, it showed statistical significance three-, four-, and five-year post-ID. These results can be explained by the fact that it would take some time for CRS to cause mouth breathing, thereby affecting the periodontal tissue.

A recent study of CRS and CP suggested that a dysbiotic biofilm elicited inflammatory sinusitis and oral diseases in the host [21,22]. This theory states that biofilm agglomeration stabilizes a microbial profile that destroys equilibrium in the host [23]. This microbiome dysbiosis theory hypothesized that Staphylococcus aureus, Streptococcus, Pseudomonas, and Anaerobes play key roles as crucial pathogens in CRS. Porpyromonas gingivalis acts as an essential pathogen in $\mathrm{CP}$, which can increase the activity of biofilm bacteria by interrupting homeostasis in the host $[5,23,24]$. Microbiome dysbiosis disrupts homeostasis between the resident microbiota and the host immune system, causing chronic inflammation that induces CRS and CP $[5,25]$.

Another explanation would be the immunological response to environmental factors $[26,27]$. The accelerated immune response to the microbiota could be related to both CRS and CP. In the respiratory epithelium of CRS patients and in the oral epithelium of $\mathrm{CP}$ patients, polymicrobial biofilms were colonized, and the biofilms were proven to be a signal source for both innate and adaptive mucosal immune responses [28,29]. Chronic exposure to pathogens, such as bacteria, viruses, fungal spores, and environmental stressors, can cause respiratory epithelial cells and oral epithelial cells to secrete cytokines (IL-1, IL-6, IL-17, TNF- $\alpha$, etc.). These cytokines activate inflammatory pathways and recruit dedicated immune cells (macrophages, dendritic cells, eosinophils, neutrophils, T cells, and NK cells) that could play a significant role in CRS and CP pathogenesis [4,30]. Microbiome dysbiosis, biofilms, and the polarization of cytokine patterns are essential for understanding the link between CRS and CP.

There are five major strengths of our study. The first advantage of this study is the large number of study participants $(n=29,755)$. The CRS group was followed-up for a maximum of 13 years, whereas another study conducted a five-year follow-up [14]. Second, the Korean National Health Insurance Service-Health Screening Cohort data was a large national survey that is representative of the Korean population. These cohort records were available for each participant. Previous studies asked participants about their history of disease, which could result in a recall bias [31,32]. On the other hand, the records used in our study were not distorted by the patient's memory. The data also involved only Koreans, and all participants without exception. Therefore, no participants were missed during the follow-up period. Third, well-trained clinicians documented the general health examinations and 
laboratory evaluations. Fourth, professional dentists conducted periodontal diagnosis and treatment. These results support the evidence of an association between CP and CRS in adults. Finally, adjusting factors showed a statistically significant independent association with CRS in our data, thus confirming the reliability of our study.

The associations found in this study were obtained by using large population data. Nevertheless, the findings had limitations. First, although the dataset included many factors such as obesity, smoking, alcohol consumption, and age, it was impossible to adjust for all systemic factors such as sugar consumption, personal oral hygiene, and oral drugs, which were not included in the large population dataset in this study. Second, this study may have presented a surveillance bias. Patients with CRS were more susceptible to be diagnosed and treated for possibly unrelated CP based on their frequent visits to the medical institutions. However, it is very unlikely that increased patient visits would induce the detection of CP. Dental examinations were performed at an annual check-up visit covered by the Korean National Health Service (KNHS), which has exclusive characteristics including widespread coverage, efficient benefits, low payment, and easy access to medical institutions in Korea. In addition to these advantages, most Koreans have undergone regular dental check-ups without discomfort. Furthermore, the large population data of this study were adjusted for many factors, thereby minimizing the surveillance bias. Therefore, this study has probably avoided or minimized surveillance bias by adjusting the characteristics of the KNHS system.

\section{Conclusions}

This study revealed that CRS patients were more likely to receive $\mathrm{CP}$ diagnosis and treatment. $\mathrm{CRS}$ and $\mathrm{CP}$ are linked to chronic inflammation. Clinicians should be aware of the possible risk of $\mathrm{CP}$ in patients with CRS.

Author Contributions: Conceptualization, B.J.P., H.G.C. and S.J.H.; data curation, C.M., H.K., B.J.P. and H.G.C.; Funding acquisition, H.G.C. and S.J.H.; Investigation, C.M., B.J.P. and H.G.C.; Methodology, H.K., S.K.K., B.J.P. and H.G.C.; Supervision, S.H.B., I.S.P., H.K., S.K.K., B.J.P., H.G.C. and S.J.H.; Writing-original draft, S.H.B., S.K.K., H.G.C. and S.J.H.; Writing-review \& editing, S.H.B., I.S.P., H.K., S.K.K., H.G.C. and S.J.H. All authors have read and agreed to the published version of the manuscript.

Funding: This research was supported by the Young Researcher Program through the National Research Foundation of Korea (NRF) funded by the Ministry of Science and ICT (MSIT) (2018R1C1B6008596). This research was supported by Hallym University Research Fund 2016 (HURF-2016-61).

Conflicts of Interest: The authors declare no potential conflicts of interest with respect to the authorship and/or publication of this article.

\section{References}

1. Ahn, J.C.; Kim, J.W.; Lee, C.H.; Rhee, C.S. Prevalence and Risk Factors of Chronic Rhinosinusitus, Allergic Rhinitis, and Nasal Septal Deviation: Results of the Korean National Health and Nutrition Survey 2008-2012. JAMA Otolaryngol. Head Neck Surg. 2016, 142, 162-167. [CrossRef] [PubMed]

2. Hamilos, D.L. Chronic rhinosinusitis: Epidemiology and medical management. J. Allergy Clin. Immunol. 2011, 128, 693-707. [CrossRef] [PubMed]

3. Fokkens, W.J.; Lund, V.J.; Mullol, J.; Bachert, C.; Alobid, I.; Baroody, F.; Cohen, N.; Cervin, A.; Douglas, R.; Gevaert, P.; et al. EPOS 2012: European position paper on rhinosinusitis and nasal polyps 2012. A summary for otorhinolaryngologists. Rhinology 2012, 50, 1-12. [CrossRef] [PubMed]

4. Stevens, W.W.; Lee, R.J.; Schleimer, R.P.; Cohen, N.A. Chronic rhinosinusitis pathogenesis. J. Allergy Clin. Immunol. 2015, 136, 1442-1453. [CrossRef] [PubMed]

5. Mahdavinia, M.; Keshavarzian, A.; Tobin, M.C.; Landay, A.L.; Schleimer, R.P. A comprehensive review of the nasal microbiome in chronic rhinosinusitis (CRS). Clin. Exp. Allergy 2016, 46, 21-41. [CrossRef] [PubMed]

6. Hopkins, C.; Surda, P.; Bast, F.; Hettige, R.; Walker, A.; Hellings, P.W. Prevention of chronic rhinosinusitis. Rhinology 2018, 56, 307-315. [CrossRef]

7. Flemmig, T.F. Periodontitis. Ann. Periodontol. 1999, 4, 32-38. [CrossRef] 
8. Albandar, J.M.; Brunelle, J.A.; Kingman, A. Destructive periodontal disease in adults 30 years of age and older in the United States, 1988-1994. J. Periodontol. 1999, 70, 13-29. [CrossRef]

9. CDC-AAP Periodontal Disease Surveillance Workgroup. J. Periodontol. 2007, 78. [CrossRef]

10. Zhang, S.; Yu, N.; Arce, R.M. Periodontal inflammation: Integrating genes and dysbiosis. Periodontol. 2000 2020, 82, 129-142. [CrossRef]

11. Bascones, A.; Gamonal, J.; Gomez, M.; Silva, A.; Gonzales, M.A. New knowledge of the pathogenesis of periodontal disease. Quintessence Int. 2004, 35, 706-716. [PubMed]

12. Socransky, S.S.; Haffajee, A.D. Dental biofilms: Difficult therapeutic targets. Periodontol. 2000 2002, 28, 12-55. [CrossRef] [PubMed]

13. Marsh, P.D. Plaque as a biofilm: Pharmacological principles of drug delivery and action in the sub- and supragingival environment. Oral Dis. 2003, 9, 16-22. [CrossRef] [PubMed]

14. Keller, J.J.; Wu, C.S.; Lin, H.C. Chronic rhinosinusitis increased the risk of chronic periodontitis: A population-based matched-cohort study. Laryngoscope 2013, 123, 1323-1327. [CrossRef]

15. Lechien, J.R.; Filleul, O.; Costa de Araujo, P.; Hsieh, J.W.; Chantrain, G.; Saussez, S. Chronic maxillary rhinosinusitis of dental origin: A systematic review of 674 patient cases. Int. J. Otolaryngol. 2014, 2014, 465173. [CrossRef]

16. Kim, S.Y.; Min, C.; Oh, D.J.; Choi, H.G. Tobacco Smoking and Alcohol Consumption Are Related to Benign Parotid Tumor: A Nested Case-Control Study Using a National Health Screening Cohort. Clin. Exp. Otorhinolaryngol. 2019, 12, 412-419. [CrossRef]

17. Quan, H.; Sundararajan, V.; Halfon, P.; Fong, A.; Burnand, B.; Luthi, J.-C.; Saunders, D.L.; Beck, C.A.; Feasby, T.A.; Ghali, W.A. Coding algorithms for defining comorbidities in ICD-9-CM and ICD-10 administrative data. Med. Care 2005, 43, 1130-1139. [CrossRef]

18. Quan, H.; Li, B.; Couris, C.M.; Fushimi, K.; Graham, P.; Hider, P.; Januel, J.-M.; Sundararajan, V. Updating and validating the Charlson comorbidity index and score for risk adjustment in hospital discharge abstracts using data from 6 countries. Am. J. Epidemiol. 2011, 173, 676-682. [CrossRef]

19. Hoare, A.; Soto, C.; Rojas-Celis, V.; Bravo, D. Chronic Inflammation as a Link between Periodontitis and Carcinogenesis. Mediat. Inflamm. 2019, 2019, 1029857. [CrossRef]

20. Wagaiyu, E.G.; Ashley, F.P. Mouthbreathing, lip seal and upper lip coverage and their relationship with gingival inflammation in 11-14 year-old schoolchildren. J. Clin. Periodontol. 1991, 18, 698-702. [CrossRef]

21. Abreu, N.A.; Nagalingam, N.A.; Song, Y.; Roediger, F.C.; Pletcher, S.D.; Goldberg, A.N.; Lynch, S.V. Sinus microbiome diversity depletion and Corynebacterium tuberculostearicum enrichment mediates rhinosinusitis. Sci. Transl. Med. 2012, 4. [CrossRef] [PubMed]

22. Hajishengallis, G.; Lamont, R.J. Beyond the red complex and into more complexity: The polymicrobial synergy and dysbiosis (PSD) model of periodontal disease etiology. Mol. Oral. Microbiol. 2012, 27, 409-419. [CrossRef] [PubMed]

23. Darveau, R.P. Periodontitis: A polymicrobial disruption of host homeostasis. Nat. Rev. Microbiol. 2010, 8, 481-490. [CrossRef] [PubMed]

24. Cope, E.K.; Goldberg, A.N.; Pletcher, S.D.; Lynch, S.V. Compositionally and functionally distinct sinus microbiota in chronic rhinosinusitis patients have immunological and clinically divergent consequences. Microbiome 2017, 5, 53. [CrossRef]

25. Bashutski, J.D.; Eber, R.M.; Kinney, J.S.; Benavides, E.; Maitra, S.; Braun, T.M.; Giannobile, W.V.; McCauley, L.K. The impact of vitamin D status on periodontal surgery outcomes. J. Dent. Res. 2011,90,1007-1012. [CrossRef]

26. Bachert, C.; Gevaert, P.; Holtappels, G.; Cuvelier, C.; van Cauwenberge, P. Nasal polyposis: From cytokines to growth. Am. J. Rhinol. 2000, 14, 279-290. [CrossRef]

27. Tripathi, A.; Kern, R.; Conley, D.B.; Seiberling, K.; Klemens, J.C.; Harris, K.E.; Suh, L.; Huang, J.; Grammer, L.C. Staphylococcal exotoxins and nasal polyposis: Analysis of systemic and local responses. Am. J. Rhinol. 2005, 19, 327-333. [CrossRef]

28. Foreman, A.; Holtappels, G.; Psaltis, A.J.; Jervis-Bardy, J.; Field, J.; Wormald, P.-J.; Bachert, C. Adaptive immune responses in Staphylococcus aureus biofilm-associated chronic rhinosinusitis. Allergy 2011, 66, 1449-1456. [CrossRef]

29. Kern, R.C.; Conley, D.B.; Walsh, W.; Chandra, R.; Kato, A.; Tripathi-Peters, A.; Grammer, L.C.; Schleimer, R.P. Perspectives on the etiology of chronic rhinosinusitis: An immune barrier hypothesis. Am. J. Rhinol. 2008, 22, 549-559. [CrossRef] 
30. Cardoso, E.M.; Reis, C.; Manzanares-Cespedes, M.C. Chronic periodontitis, inflammatory cytokines, and interrelationship with other chronic diseases. Postgrad. Med. 2018, 130, 98-104. [CrossRef]

31. Paradise, J.L.; Bluestone, C.D.; Colborn, D.K.; Bernard, B.S.; Rockette, H.E.; Kurs-Lasky, M. Tonsillectomy and adenotonsillectomy for recurrent throat infection in moderately affected children. Pediatrics 2002, 110, 7-15. [CrossRef] [PubMed]

32. Van Staaji, B.K.; van den Akker, E.H.; Rovers, M.M.; Hordijk, G.J.; Hoes, A.W.; Schilder, A.G. Effectiveness of adenotonsillectomy in children with mild symptoms of throat infections or adenotonsillar hypertrophy: Open, randomised controlled trial. Clin. Otolaryngol. 2005, 30, 60-63. [CrossRef] [PubMed]

(C) 2020 by the authors. Licensee MDPI, Basel, Switzerland. This article is an open access article distributed under the terms and conditions of the Creative Commons Attribution (CC BY) license (http://creativecommons.org/licenses/by/4.0/). 